\title{
Fifty years of the Journal of Geometry
}

\author{
Hans Havlicek@ and Alexander Kreuzer
}

The first issue of the Journal of Geometry was published 50 years ago, in spring 1971. In this note, which is part of a topical collection of invited papers on the occasion of this anniversary, the managing editors aim at presenting several aspects of the journal's history.

The driving force for the establishment of the journal was Walter Benz (19312017). His academic career began in West Germany, where he taught at the Universities of Mainz (1961), Frankfurt (1961-1965), and Würzburg (19631964) before he became full professor at the University of Bochum in 1966. After staying at the University of Waterloo, Canada (1966-1967 and 1969), Walter Benz was appointed as full professor at the University of Hamburg in 1974.

After good preparatory work, most of the founding editors of the Journal of Geometry attended the international Geometry Meeting held at the University of Waterloo, Canada, from March 19 to 27, 1971. Talks at this conference were given by J. Aczél (Waterloo), J.J. Arnold (Bochum), R. Artzy (Philadelphia), A. Barlotti (Perugia), W. Benz (Bochum/Waterloo), R.C. Bose (Chapel Hill), J. Brown (Toronto), Y. Chen (Waterloo), H.S.M. Coxeter (Toronto), D.W. Crowe (Madison), L. Dickey (Waterloo), J. Doyen (Brussels), L. Dubikajtis (Torun), E. Ellers (Toronto), G. Ewald (Bochum), H.J. Groh (Thunder Bay), W. Heise (Hannover), D.R. Hughes (London), W. Jonsson (Montreal), K.R. Kannenberg (Stellenbosch/Bochum), H. Karzel (Hannover), P.A. Lawrence (Waterloo), W. Leißner (Bochum/Waterloo), H. Mäurer (Darmstadt), R.L. McFarland (Columbus), I. Pieper (Hamburg), F. Radó (Cluj), H. Schaeffer (Bochum), P. Scherk (Toronto), N.K. Stephanidis (Thessaloniki) and P. Vamos (Sheffield). Based upon successful negotiations of Walter Benz with the publishing house Birkhäuser Verlag (Basel, Switzerland), which was represented by Carl Eisele, the first issue of the newly established journal went into print shortly after the meeting.

During our journal's early years, each volume consisted of two issues, which were generally published in March and September. Later, two volumes 
appeared per year and since 1987 in general three volumes per year, each volume containing two issues. Since Vol. 103 (2012), we publish one volume per year divided in three issues, which become due in April, August and December.

A change of publishing policy took place beginning with Vol. 109 (2018). Following a suggestion of Birkhäuser, which in the meantime had turned into a branch of Springer Nature Switzerland, we switched to what is known under the name continuous article publication. According to its principles, all accepted papers are, on the one hand, published online in a timely manner on the journal's website and, on the other hand, immediately assigned to the next available issue (rather than receiving the temporary status of online first publication, as was done before). By doing so, we were able to decrease the period between the submission of a paper and its publication.

In total, by the end of August 2021, more than 2100 papers have been published in 112 volumes of the Journal of Geometry. Most of these publications are research papers, a few deal with the life and work of geometers. Our journal published special volumes containing papers related to the talks given at conferences:

- Vol. 67 (2000) consists of work presented at the Second Pythagorean Conference-An Advanced Research Workshop in Geometry, Combinatorial Designs and Related Structures, which took place at Pythagoreion, Samos, Greece, from 31 May to 5 June 1999;

- Vol. 101 (2011) comprises 14 papers reflecting most of the invited lectures at the meeting Combinatorics 2010, held in Verbania, Italy, from 27 June to 3 July 2010.

We also published brief summaries about various meetings as well as the abstracts of talks presented at a series of conferences:

- International Conference on Geometry, held repeatedly at the University of Haifa, Israel (1975-1999);

- Geometrie Seminar, held at Aristotle University Thessaloniki, Greece (1977);

- International Conference on Geometry, held at Schloss Rauischholzhausen, a conference venue of Justus Liebig University Giessen, Germany (1990);

- The Klee-Grünbaum Festival on Geometry, held in Ein Gev, Israel (2000);

- International Conference on Geometry and Applications, which took place every other year in Saints Constantine and Helena near Varna, Bulgaria (2001-2019);

- Combinatorics 2002, held in Maratea (2002);

- Third Symposium on Geometry, held at Eskişehir-Osmangazi University, Turkey (2005).

In Vol. 7 (1976) and Vol. 16 (1981), two detailed bibliographies about Hjelmslev incidence geometries and related topics came out. These bibliographies were extended to another publication entitled Literature on geometry over rings, 
which is one of the papers in Vol. 42 (1991). In those days, a publication in an international journal was probably the most efficient way to disseminate information of this kind. Today, however, there are many other means of communication for sharing such an uncommented list of references with colleagues all around the world.

The cover page and the first inner sleeve of Vol. 1 (1971), Issue 1, are displayed in Figs. 1 and 2, respectively. The cover page tells us that this issue contains five articles, two in English and three in German. As a matter of fact, the second issue of Vol. 1 comprises a total of eight articles, six in English and two in German. These numbers already illustrate that, up to the end of the 1980's, writing articles in languages other than English was quite common among mathematicians. For example, during the first twenty years, that is from 1971 to 1990, approximately 640 articles appeared in the Journal of Geometry. Out of these, about one third was authored in German, less than ten were written in French and the remaining ones in English. After the year 1990, the number of non-English submissions to our journal decreased drastically, and gradually writing papers in a language other than English has become quite uncommon.

The preface on the inner sleeve (Fig. 2) outlines the journal's aims and scope at the time of its establishment. It goes without saying that the subdisciplines of mathematics mentioned there reflect the main research areas of the editors at that time. Over the decades, some changes took place. Today, the Journal of Geometry is devoted to the publication of current research developments in the fields of geometry, and in particular of recent results in foundations of geometry, geometric algebra, finite geometries, combinatorial geometry and differential geometry.

The text of the inner sleeve also allows us to learn more about the motivation for the founding editors: it was the absence of a journal that would focus on research in geometry. Their goal was by no means to weaken the interaction of geometry with other areas of mathematics, but to establish a new journal as a complement to all those well established journals that would cover a wide range of mathematics.

We also may read off from Fig. 2 the names of the founding editors, who came from Canada, Italy, Romania, the U.S.A. and West Germany: Rafael Artzy (1912-2006), Adriano Barlotti (1923-2008), Martin Barner (1921-2020), Walter Benz (1931-2017), Raj Chandra Bose (1901-1987), Henry Crapo (19322019), Werner Heise (1944-2013), Helmut Karzel (1928-1921), Werner Leißner, Rolf Lingenberg (1929-1978), Ferenc Radó (1921-1990), Giuseppe Tallini (1930-1995).

In the course of time, the composition of the editorial board changed, members passed away, a few members resigned, and new members were appointed. We wish to acknowledge the substantial work of the following former editors: János D. Aczél (1924-2020), Waterloo, Canada; Pier Vittorio Ceccherini, Roma, Italy; Udo Hertrich-Jeromin, Wien, Austria; Jorge H.S. de Lira, Fortaleza, Brazil; Theodore G. Ostrom (1916-2011), Pullman, WA, U.S.A.; Boyan 


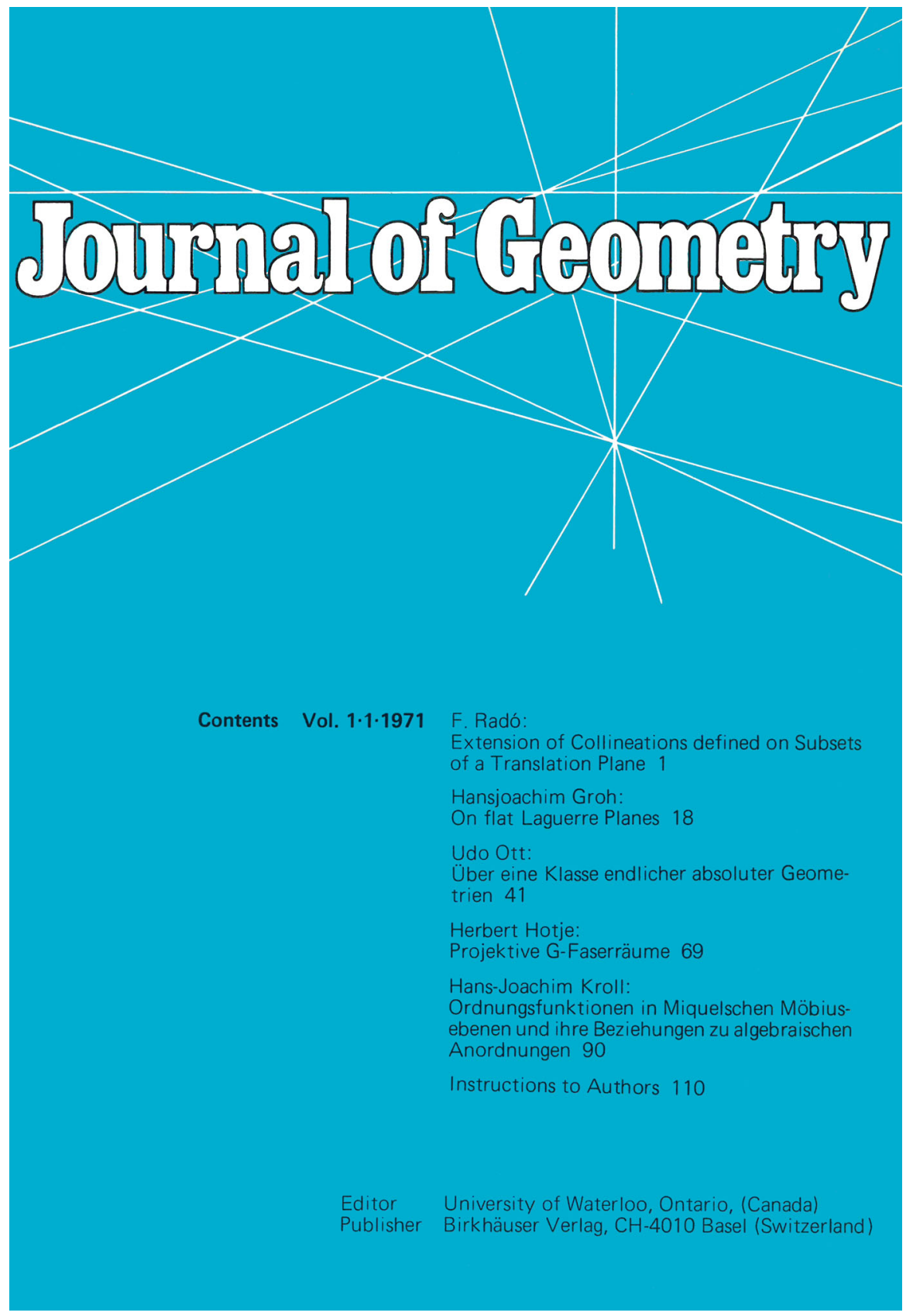

Figure 1 Cover page of Vol. 1, Issue 1 
"The "Journal of Geometry" is devoted to the publications of current developments in Geometry, particulary of recent results in Foundations of Geometry, Geometric Algebra, Finite Geometries, Combinatorial Geometry, and special geometries. Although Geometry is a discipline dominating the interest and efforts of a great many mathematicians throughout the world, to date there has been no journal devoted specifically to these topics. It is hoped that the "Journal of Geometry" will help to fill the gap."

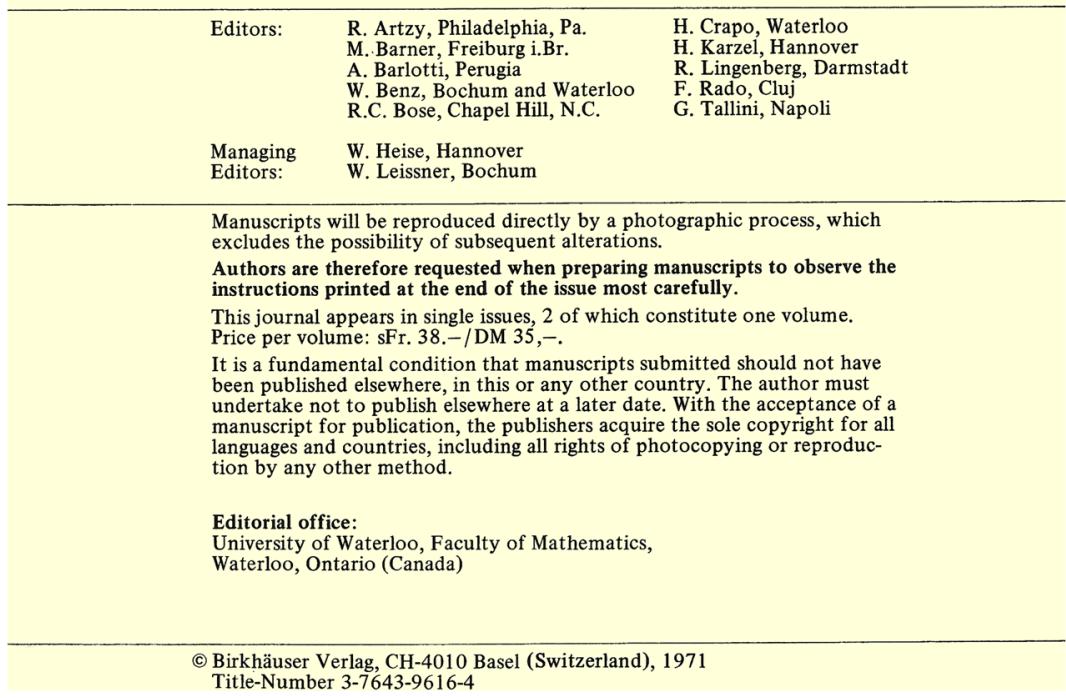

Figure 2 Inner sleeve of Vol. 1, Issue 1

L. Petkanchin (1908-1987), Sofia, Bulgaria; Joseph Zaks (1940-2018), Haifa, Israel.

The journal's Honorary Board has been established in 2017. It comprises mathematicians who have been editors of the journal for many years and continue supporting our work at their own discretion. As of August 2021, its members are: James W.P. Hirschfeld, Brighton, United Kingdom; Hans-Joachim Kroll, München, Germany; Werner Leißner, Oldenburg, Germany; Mario Marchi, Brescia, Italy; Maria Scafati Tallini, Rome, Italy; Grozio Stanilov, Sofia, Bulgaria; Nikolaus K. Stephanidis, Thessaloniki, Greece. 
At the time of writing, the Editorial Board consists of the following researchers: Simeon Ball, Barcelona, Spain; Anton Betten, Fort Collins, CO, U.S.A.; Bart de Bruyn, Gent, Belgium; Hans Havlicek, Wien, Austria; Zejun Hu, Zhengzhou, China; Franz Kalhoff, Dortmund, Germany; Alexander Kreuzer, Hamburg, Germany; Ivan Landjev, Sofia, Bulgaria; Guglielmo Lunardon, Napoli, Italy; Gábor P. Nagy, Szeged, Hungary; Silvia Pianta, Brescia, Italy; Markus Stroppel, Stuttgart, Germany.

The first managing editors were Werner Heise and Werner Leißner. They served for several years, before Walter Benz took over the management. Hans-Joachim Kroll was in charge of editing the Journal of Geometry for more than 30 years, from Vol. 17 (1981) up to the second issue of Vol. 104 (2013). The authors of this note, Hans Havlicek and Alexander Kreuzer, are his successors. In order to acknowledge his outstanding work, Hans-Joachim Kroll has been appointed as Honorary Editor of the journal in 2013.

In conclusion, we wish to express our gratitude to numerous colleagues, who supported our journal by providing their expertise in the course of peer reviewing. Our thanks also go to executives of Springer Nature, in particular to Thomas Hempfling, Clemens Heine and Antje Herbst, for their support during the last years and for providing an infrastructure that allows us to manage the editorial process in an efficient way.

Publisher's Note Springer Nature remains neutral with regard to jurisdictional claims in published maps and institutional affiliations.

Hans Havlicek

Institut für Diskrete Mathematik und Geometrie

Wiedner Hauptstraße 8-10

1040 Wien

Austria

e-mail: havlicek@geometrie.tuwien.ac.at

Alexander Kreuzer

Fachbereich Mathematik

Bundesstraße 55

20146 Hamburg

Germany

e-mail: kreuzer@math.uni-hamburg.de

Received: September 28, 2021. 